\title{
Production of Ligninolytic Enzymes by Cultures of White Rot Fungi
}

\author{
EWA B. GÓRSKA ${ }^{1}$, URSZULA JANKIEWICZ², JAKUB DOBRZYŃSKI ${ }^{1}$, AGNIESZKA GAŁĄZKA², \\ MONIKA SITAREK ${ }^{3}$, DARIUSZ GOZDOWSKI ${ }^{5}$, STEFAN RUSSEL ${ }^{4}$ and PAWEE KOWALCZYK ${ }^{*}$ \\ ${ }^{1}$ Department of Microbial Biology Faculty of Agriculture and Biology, Warsaw University \\ of Life Sciences-SGGW, Warsaw, Poland \\ ${ }^{2}$ Department of Biochemistry, Faculty of Agriculture and Biology, Warsaw University \\ of Life Sciences- SGGW, Warsaw, Poland \\ ${ }^{3}$ Faculty of Horticulture, Biotechnology and Landscape Architecture, Department of Vegetable \\ and Medicinal Plants, Warsaw University of Life Sciences-SGGW, Warsaw, Poland \\ ${ }^{4}$ Institute Technology and Life Sciences in Falenty, Raszyn, Poland \\ ${ }^{5}$ Department of Experimental Statistics and Bioinformatics, Faculty of Agriculture and Biology, \\ Warsaw University of Life Sciences-SGGW, Warsaw, Poland \\ ${ }^{6}$ Bionicum LTD, Warsaw, Poland
}

Submitted 24 May 2014, revised 20 September 2014, accepted 29 September 2014

\begin{abstract}
Some Basidiomycota were chosen for studies of key ligninases synthesis $\left(25^{\circ} \mathrm{C}, 30\right.$ days) in modified medium (shaken or not cultures) with added wheat straw. Liquid Czapek medium with straw yielded a higher amount of laccase than peroxidase, ground straw induced enzyme worse than chopped straw. With peroxidase the reverse dependencies were observed. Laccase of Lentinus edodes synthesized two enzyme isoforms ( $c a 30$ and $16 \mathrm{kDa}$ ). In T. versicolor culture active laccase protein with highest molecular mass $c a 65 \mathrm{kDa}$ was found. P. sajor-caju yielded three different peroxidase isoforms. Ligninase biosynthesis depended on strain, straw fragmentation extent, culture method and growth medium.
\end{abstract}

Key words: Basidiomycota, degradation of straw, laccase, peroxidase

Wood-degrading white rot fungi belonging to the phylum Basidiomycota degrade lignin in the natural environment under aerobic conditions by virtue of synthesizing ligninolytic enzymes that include the laccases (polyphenol oxidases EC 1.10.3.2) and lignin peroxidases (E.C.1.11.1.7) (Jung et al., 2002; Sanchez, 2009). Both enzymes, depending on the part of the world, are produced using fungal cultures and lignocellulose substrates of varied origin. Laccases are secreted by higher plants, fungi and some bacteria (Claus, 2003; Hutterman et al., 2001). These enzymes are characterized by broad substrate specificity, they oxidize phenolic compounds, aromatic amines and lignins, amongst others, reducing molecular oxygen to water (Riva, 2006). Laccase is capable of performing not only oxidation but other reactions which include even aromatic ring breaking. In the presence of appropriate mediators they are also capable of delignification of wood pulp and carrying out the oxidation of aromatic alcohols with high redox potential (Du et al., 2013), In recent years a number of papers have described insects as laccase producers. Fungi, mainly the Basidiomycota, produce more than two types of peroxidases that play a key role in the degradation of lignins: a manganese peroxidase and a lignin peroxidase (Martinez, 2007). Fungi usually synthesize many isoforms of these enzymes, thus ensuring the degradation of various substrates, including lignins, aromatic and humic compounds as well as xenobiotics, including phenanthrene and pyrene (Hofrichter, 2002). Interest in ligninolytic enzymes grown from year to year because of their potential broad application in various industrial fields (Kunamneni et al., 2008). Consequently, the considerable amounts of lignocellulose side or waste products from agriculture, forestry, sawmill industry, woodworking industry, furniture industry, milling industry, papermaking industry and the fermentation, fruits and vegetables industry, may find use in biotechnology for the large scale production of ligninases. One of such lignocellulose substrates is straw from grain crops, which depending on the type of plant can contain from about 30 to over $40 \%$ of crude fiber (mainly lignin and cellulose) as dry weight, which when added do culture media for Basidiomycota fungi is used to induce the synthesis of ligninases (Koroleva

\footnotetext{
* Corresponding author: P. Kowalczyk, Bionicum LTD, Warsaw, Poland; e-mail: pawel.kowalczyk@bionicum.com.pl
} 
et al., 2002; Mayer and Staples, 2002; Michael et al., 1991; Morais et al., 2009; Shah etal., 2005). The aim of these studies was to determine the level of ligninase production in cultures of fungi classified to the phylum Basidiomycota supplemented with wheat straw, a byproduct of the main grain crop cultivated in Poland, as an inducer of ligninases, depending on the degree of fragmentation of lignocellulose substrate and composition of culture medium.

The enzymatic studies embraced fungi belonging to the phylum Basidiomycota from the collection of the Department of Biochemistry, Maria Curie-Skłodowska University in Lublin: Pleurotus ostreatus 246 and Lentinus edodes 169 (Fungal Culture Collection of Forest Products Chemistry Laboratory, Tokyo, Japan); Pleurotus ostreatus 251 and Lentinus edodes 279 (Forest Products College of Agriculture Changbuk National University of Choengju, South Korea), Medical University in Warsaw Pleurotus sajor-caju; Asia Pacific Natural Agriculture Network, Bangkok, Thailand - Pleurotus ostreatus 6, University of Alexandria, Egypt - Trametes versicolor and Phanerochaete chrysosporium. Fungal strains were grown and stored at $5^{\circ} \mathrm{C}$ on potato-glucose agar (PDA) with slants or/in Czapek's agar medium (Burbianka et al., 1983). The activity of select ligninolytic fungal enzymes was determined in cultures set up in modified liquid Czapek (Burbianka et al., 1983) or potato-glucose media (PDE), in which saccharose or glucose, respectively, were replaced with $1 \%$ straw from Korweta winter wheat. Before preparing the growth media straw that was either ground or cut into 3 do $5 \mathrm{~cm}$ lengths was sterilized three times at $121^{\circ} \mathrm{C}$. Fungi were grown on PDA at $25^{\circ} \mathrm{C}$. After 10 day incubation ten $10 \mathrm{~mm}$ diameter discs were cut using sterile precautions out of each medium media overgrown with mycelium, which were transferred under sterile conditions to $500 \mathrm{ml}$ Erlenmayer flasks containing $100 \mathrm{ml}$ liquid of potato-glucose medium. After 10 days of incubation at $25^{\circ} \mathrm{C}$ in shaking water bath $(130 \mathrm{rev} . / \mathrm{min})$ $10 \mathrm{ml}$ of homogenized of fungal mycelium suspension was removed from the culture (inoculum) and transferred to $100 \mathrm{ml}$ of modified production medium in which saccharose or glucose, respectively, were replaced with $1 \%$ straw from Korweta winter wheat (containing straw with varying degree of fragmentation from 3 to $5 \mathrm{~cm}$ length). Fungi were grown in three parallel cultures under stationary conditions without agitation or agitated in shaking water bath $(150 \mathrm{rev} . / \mathrm{min})$ at $25^{\circ} \mathrm{C}$. After 30 days the cultures were passed through Schott G1 filter coupled to vacuum filtration setup. Long time incubation is connected with decomposition of cellulose substances by lignolytic enzymes. The choice of the term was confirmed preliminary research where the highest activity of enzymes was observed after 30 day of incubation. Because breeding was carried out in a large volume of $100 \mathrm{ml}$ volumetric flasks, of capacity $500 \mathrm{ml}$ of a suitable with narrow neck what stopped evaporation and in an air-conditioned room with a constant temperature and humidity. Laccase activity in culture filtrates was determined with the use of syringaldehyde (4-hydroxy-3,5-dimethoxybenzaldehyde) as the substrate and peroxidase activity was assayed using the substrate pyrogallol (Leonowicz and Grzywnowicz, 1998; Toczko and Grzelińska, 1997). A unit (U) of laccase activity was taken as the amount of enzyme releasing $1 \mu \mathrm{mol}$ products formed by the oxidation of $1 \mu \mathrm{mol}$ syringaldehyde in one minute calculated per $100 \mathrm{ml}$ filtrate, whereas a unit of peroxidase activity was taken as the amount of enzyme releasing $1 \mu \mathrm{mol}$ purpurgallin in one minute calculated per $100 \mathrm{ml}$ filtrate. The results of enzymatic analyses were verified by singleand multi-factor variance analysis using the program Statgraphics plus 4.0. Homogeneous sets were determined using Tukey's test for $\alpha=0.05$. Laccase activity was detected on zymograms following electrophoretic separation under reducing conditions of 5-fold concentrated (Viva spin, Sigma) culture filtrates showing highest enzymatic activity. To detect laccase isoforms for the individual fungal strains electrophoresis was carried out under denaturing conditions in $12 \%$ polyacrylamide gel, after which the gels were incubated in $40 \mathrm{mM}$ ABTS $100 \mathrm{mM}$ Mc Ivaine buffer, $\mathrm{pH}$ 4.7; green bands against the background of unstained gel indicated the presence of active enzyme in the culture filtrates (Niku-Paavola et al., 1990). The location of laccase activity bands on the gel with respect to standard proteins allowed the estimation of molecular masses.

The studied fungi grown in modified Czapek medium synthesized different amounts of laccase and peroxidase regardless of the degree of fragmentation of the straw and culture conditions (Table I). It was observed that whereas agitation of the fungal cultures increased the production of laccase, the lack of agitation reduced the synthesis of the enzyme and vice versa. Similar relations were found in the case of peroxidase production. Of the eight studied fungal strains only P. ostreatus 246 produced the highest amount of laccase in medium containing ground straw that was not shake (Table I). In shaken cultures strains P. ostreatus 251, P. sajor-caju and T. versicolor produced the highest amounts of the studied enzyme compared to the remaining studied fungi (Table I). On average, wheat straw with lesser degree of fragmentation (cut) was a better inducer of laccase synthesis in both fungal culture conditions in Czapek medium than ground straw. The only exception was P. ostreatus 246, which produced half as much laccase in unshaken culture supplemented with cut straw compared to the ground substrate. In shaken cultures supplemented with wheat chopped straw P. ostreatus 251 synthesized the highest amounts of laccase; comparable enzyme activity was observed only in the case of P. ostreatus 246 (Table I). 
Table I

Mean laccase and peroxidase activity $\left(\mathrm{U} \times 100 \mathrm{ml}^{-1}\right)$ in culture filtrates of the studied fungi grown using various methods in Czapek medium containing 1\% wheat straw with different degree of fragmentation (different letters indicate significantly differing means in columns for the type of culture)

\begin{tabular}{|c|c|c|c|c|}
\hline \multirow{3}{*}{ Basidiomycota strains } & \multicolumn{2}{|c|}{ Ground straw } & \multicolumn{2}{|c|}{ Cut straw } \\
\hline & \multicolumn{4}{|c|}{ Culture } \\
\hline & unshaken & shaken & unshaken & shaken \\
\hline \multicolumn{5}{|c|}{ Laccase } \\
\hline 1. P. ostreatus 246 & $1024.0 \mathrm{~b}$ & $25.6 \mathrm{a}$ & $5424 \mathrm{~cd}$ & $574.5 \mathrm{bc}$ \\
\hline 2. P. ostreatus 251 & $8.4 \mathrm{a}$ & $102.5 \mathrm{ab}$ & $136.2 \mathrm{ab}$ & $727.8 \mathrm{c}$ \\
\hline 3. P. ostreatus 6 & $62.2 \mathrm{a}$ & $15.8 \mathrm{a}$ & $480.8 \mathrm{bcd}$ & $122.8 \mathrm{ab}$ \\
\hline 4. P. sajor-caju & $129.7 \mathrm{a}$ & $162.9 \mathrm{~b}$ & $274.1 \mathrm{~d}$ & $152.4 \mathrm{ab}$ \\
\hline 5. L. edodes 169 & $22.7 \mathrm{a}$ & $15.1 \mathrm{a}$ & $68.2 \mathrm{a}$ & $110.2 \mathrm{a}$ \\
\hline 6. L. edodes 279 & $10.9 \mathrm{a}$ & $36.0 \mathrm{a}$ & $88.8 \mathrm{a}$ & $102.3 \mathrm{a}$ \\
\hline 7. T. versicolor & $8.0 \mathrm{a}$ & $63.3 \mathrm{ab}$ & $183.1 \mathrm{abcd}$ & $14.5 \mathrm{a}$ \\
\hline 8. Ph.chrysosporium & $5.2 \mathrm{a}$ & $40.5 \mathrm{a}$ & $160.1 \mathrm{abc}$ & $97.4 \mathrm{a}$ \\
\hline $\operatorname{LSD}_{\alpha=0.5}$ & 389.964 & 106.064 & 382.446 & 462.316 \\
\hline \multicolumn{5}{|c|}{ Peroxidase } \\
\hline 1. P. ostreatus 246 & $0.91 \mathrm{ab}$ & $1.00 \mathrm{a}$ & $2.30 \mathrm{c}$ & $0.72 \mathrm{~d}$ \\
\hline 2. P. ostreatus 251 & $2.06 \mathrm{ab}$ & $0.93 \mathrm{a}$ & $0.10 \mathrm{a}$ & $2.27 \mathrm{e}$ \\
\hline 3. P. ostreatus 6 & $0.88 \mathrm{a}$ & $2.10 \mathrm{a}$ & $0.05 \mathrm{a}$ & $0.54 \mathrm{bcd}$ \\
\hline 4. P. sajor-caju & $0.61 \mathrm{a}$ & $3.40 \mathrm{a}$ & $0.22 \mathrm{a}$ & $0.27 \mathrm{ab}$ \\
\hline 5. L.edodes 169 & $3.75 \mathrm{abc}$ & $0.94 \mathrm{a}$ & $2.20 \mathrm{c}$ & $0.73 \mathrm{~d}$ \\
\hline 6. L. edodes 279 & $6.13 \mathrm{bcd}$ & $3.50 \mathrm{a}$ & $0 \mathrm{a}$ & $0.07 \mathrm{a}$ \\
\hline 7. T. versicolor & $10.60 \mathrm{~d}$ & $5.10 \mathrm{a}$ & $1.42 \mathrm{~b}$ & $0.34 \mathrm{abc}$ \\
\hline 8. Ph.chrysosporium & $7.36 \mathrm{~cd}$ & $30.00 \mathrm{~b}$ & $0.12 \mathrm{a}$ & $0.61 \mathrm{~cd}$ \\
\hline $\mathrm{LSD}_{\alpha=0.5}$ & 5.24828 & 14.1296 & 0.36819 & 0.28898 \\
\hline
\end{tabular}

The results presented in Table I show that the fungal strains produced lower amounts of the peroxidase, compared to laccase, regardless of culture conditions employed. Phanerochaete chrysosporium was found to be the best peroxidase-producing strain in shaken culture with ground straw.

No peroxidase activity was found in L.edodes 279 cultures in Czapek medium containing chopped straw. The presented zymogram of culture filtrates shows that the studied strains released to the culture medium laccase with varied molecular mass. Under the conditions used only strains of L.edodes secreted two isoforms of laccase with low molecular mass each, respectively, molecular mass approx. $95 \mathrm{kDa}$ and $50 \mathrm{kDa}$, in case of P. chrysosporium only single form of enzymes of mass approximately $90 \mathrm{kDa}$ was secreted. Active laccase protein with highest molecular mass of approx. $65 \mathrm{kDa}$ was observed for T. versicolor. P. ostreatus strains synthesized a single form of laccase with mass approx. $60 \mathrm{kDa}$ and for P. sajor-caju with mass approx. $25 \mathrm{kDa}$.

At the same time the fungi were grown in PDE medium with the addition of $1 \%$ ground straw wheat. Most of the investigated strains grown in this medium produced higher amounts of laccase and peroxidase than in Czapek medium, regardless of culture method used (Table II). P. sajor-caju proved the best fungus of all those studied in the production of laccase in potato medium regardless of culture conditions whereas it synthesized peroxidase the best in shaken culture. Similarly as in Czapek medium, shaking of fungal cultures in PDE medium increased the production of laccase and peroxidase, whereas lack of agitation reduced the synthesis of enzymes (Table II).

For many years in vitro studies have been carried out on the synthesis and activity of inducible ligninolytic enzymes, the most important of which are laccase and peroxidase produced by so-called white rot fungi, which degrade lignins the most effectively. Different lignocellulosic substrates are used to induce the synthesis of ligninases, including straw from grain crops (Koroleva et al., 2002; Morais et al., 2001; Shah et al., 2005). Enzymatic studies utilizing zymograms and colorimetric methods demonstrated that eight species of fungi belonging to the phylum Basidiomycota, produced laccase and peroxidase in both using medium supplemented with the wheat straw. The mean amount of laccase in submerged fungal cultures was significantly higher, regardless of method, than that of peroxidase, which is compatible with the results of Koroleva et al. (2002), Mayer and Staples (2002). 
Table II

Activity of studied ligninases $\left(\mathrm{U} \times 100 \mathrm{ml}^{-1}\right)$ in culture fluids of fungi grown using different methods in PDE medium supplemented with $1 \%$ ground wheat straw (different letters indicate significantly differing means in the type of culture columns)

\begin{tabular}{|l|c|c|c|c|}
\hline \multirow{2}{*}{ Basidiomycota strains } & \multicolumn{2}{|c|}{ Laccase } & \multicolumn{2}{c|}{ Ceroxidase } \\
\cline { 2 - 5 } & \multicolumn{4}{|c|}{ Culture } \\
\cline { 2 - 5 } & unshaken & shaken & unshaken & shaken \\
\hline 1. P.ostreatus 246 & $537.9 \mathrm{ab}$ & $15.8 \mathrm{a}$ & $1.72 \mathrm{ab}$ & $1.45 \mathrm{a}$ \\
\hline 2. P.ostreatus 251 & $15.4 \mathrm{a}$ & $36.4 \mathrm{a}$ & $1.88 \mathrm{ab}$ & $0.85 \mathrm{a}$ \\
\hline 3. P.ostreatus 6 & $375.5 \mathrm{ab}$ & $28.5 \mathrm{a}$ & $4.20 \mathrm{~b}$ & $1.33 \mathrm{a}$ \\
\hline 4. P. sajor-caju & $2781.9 \mathrm{c}$ & $2028.3 \mathrm{c}$ & $2.60 \mathrm{ab}$ & $74.60 \mathrm{~b}$ \\
\hline 5. L. edodes 169 & $9.2 \mathrm{a}$ & $39.7 \mathrm{a}$ & $1.00 \mathrm{a}$ & $3.10 \mathrm{a}$ \\
\hline 6. L. edodes 279 & $17.7 \mathrm{a}$ & $725.2 \mathrm{~b}$ & $24.20 \mathrm{c}$ & $1.10 \mathrm{a}$ \\
\hline 7. T. versicolor & $1026.0 \mathrm{~b}$ & $30.0 \mathrm{a}$ & $1.80 \mathrm{ab}$ & $5.20 \mathrm{a}$ \\
\hline 8. Ph. chrysosporium & $31.0 \mathrm{ab}$ & $146.6 \mathrm{a}$ & $10.20 \mathrm{~b}$ & $3.80 \mathrm{a}$ \\
\hline LSD $\mathrm{D}_{\alpha=0.5}$ & 1000.11 & 465.14 & 36.0849 & 55.0441 \\
\hline
\end{tabular}

The reason for this may be, among others, the ability of laccase to degrade lignins without synergistic cooperation with other ligninases, which has not been observed for peroxidase activity (Galliano et al., 1991; Mayer and Staples, 2002). For this reason fungi that synthesize laccase do not have to produce significant amounts of peroxidases. The extent of fragmentation of wheat straw significantly affected the biosynthesis of the studied ligninases by fungal cultures in Czapek medium, which is compatible with the results obtained by Criquet et al. (1999), who showed that ground substrate increased laccase activity. Our studies have shown reverse relations for the production of both laccase and peroxidase (Table I). The biosynthesis of laccase was higher in fungal culture with chopped straw, whereas that of peroxidase was higher in medium with ground straw. This can be explained among others by different access to oxygen of the mycelium in culture with straw with varying degrees of fragmentation. The chopped straw did not form compact pellets with the mycelium, which are known to limit the access of oxygen the hyphae of the mycelium (Nazareth and Sampy, 2003). This is why media supplemented with cutting straw ensured optimal conditions for the biosynthesis of laccase. Ground straw together with hyphae of the mycelium forms aggregates that could restrict the access of oxygen for inside of aggregates, which in consequence could reduce the production of laccase. At the same time ground straw, by limiting laccase production and thus the intensity of the degradation of lignin, impeded the access of the mycelium to nitrogen compounds in the straw of grain crops after the depletion of the mineral nitrogen from the medium, which increased the secretion of peroxidase to the medium (Krajewski and Witomski, 2003). Since microorganisms degrade lignin oxidatively, the fungal cultures were set up using two methods - with and without agitation. Although agitation of the culture medium ensured the similar oxygen concentration in the whole culture volume, this did not always result in increased enzymatic activity. However, on the average biosynthesis of laccase in unshaken cultures of the studied fungi was higher than in shaken cultures, whereas in the case of peroxidase the reverse relationship was determined (Table I). Nazareth and Sampy (2003) demonstrated the negative effect of agitation of fungal cultures on laccase production. The authors attributed this to mechanical damage to the mycelium during agitation and its negative effect on fungal growth and synthesis of enzymes as well as to changes in $\mathrm{CO}_{2}$ concentration in the medium (Zadrazil, 1975). However, this is not a rule that relates to all lignin-degrading fungi, as shown by our own studies. Agitation of P. ostreatus 251 culture increased the biosynthesis of laccase about 12 -fold compared to unshaken culture (Table I), which is in agreement with those of Jung et al. (2002). The higher production of the enzyme under agitation conditions may be the result of varied resistance of fungal hyphae to mechanical damage caused by shaking the culture as well as different requirements regarding oxygen and $\mathrm{CO}_{2}$ concentration in the mycelium growth phase. In the literature there are several papers describing the fungi of the phylum Basidiomycota producing different numbers of laccase isoforms (Bertrand et al., 2013; Karp et al., 2012; Lettera et al., 2010; Libardi et al., 2012), which has been confirmed by the results of our studies. All the fungal strains investigated by us with the exception of Lentinus edodes produced only one isoform of the laccase. Lentinus edodes strains synthesized two isoforms of laccase, which is similar to the isoforms produced by T. versicolor HEMIN-9 (Bertrand, 2013). Libardi et al. (2012) using banana peels as a source of carbon observed the 
synthesis of two laccase isoforms with mass $58.7 \mathrm{kDa}$ and $21 \mathrm{kDa}$ by P. ostreatus DSM 1833 . The isoform of laccase with size $21 \mathrm{kDa}$ described by these authors is similar in size to the isoforms produced by P. ostreatus 246, P. ostreatus 251 and P. ostreatus 6 (ok. $25 \mathrm{kDa}$ ) in our studies. The intensity of the biosynthesis of ligninolytic enzymes by Basidiomycota cultures depends on the biologically active substances present in the growth environment of fungi, as demonstrated by Eriksson and Blanchette (1990), as well as by the authors of the results presented herein. On average higher activity of ligninases in post-culture fluids of fungi maintained in modified PDE medium containing ground wheat straw compared to enzyme activity in Czapek medium was obtained. Modified potato medium (PDE) is richer in nutrients than modified Czapek medium since it contains $4 \mathrm{~g}$ potato extract per $1000 \mathrm{ml}$ medium. Besides potato extract the medium was also supplemented with a small amount of starch and the amino acids aspartic acid, glutamic acid, leucine, lysine, phenylalanine, serine, threonine, arginine, tyrosine and others. The added chemical compounds stimulate the growth of heterotrophic microorganisms, including fungi, as well as their enzymatic activity, which has been confirmed in laboratory studies by Ruttimann-Johnson et al. (1993), Shi et al. (1997). Wheat straw, which is an agricultural byproduct, is a good inducer for the synthesis of key ligninolytic enzymes (laccase and peroxidase) in cultures of fungi from the phylum Basidiomycota selected for the study. The synthesis of ligninolytic enzymes is affected by choice of strain, as well as by various abiotic factors (degree of straw fragmentation, culture method, composition of culture medium).

\section{Literature}

Bertrand B., F. Martínez-Morales, R. Tinoco, S. Rojas-Trejo, L. Serrano-Carreón and M.R. Trejo-Hernández. 2013. Induction of laccases in Trametes versicolor by aqueous wood extracts. World J. Microbiol. Biotechnol. 30: 135-142.

Burbianka M., M. Pliszka and H. Burzyńska. 1983. Food Microbiol. (in Polish)PZWL, Wyd 5. Warsaw 520.

Claus H. 2003. Laccases and their occurrence in prokaryotes. Arch. Microbiol. 179: 145-150.

Criquet S., S. Tagger, G. Vogt, G. Iacasio and J. Le Petit. 1999. Laccase activity of forest litter. Soil Biol. Biochem. 31: 1239-1244.

Du Xueyu Li J., G. Gellerstedt, J. Rencoret, J. C. Del Río, A.T. Martínez and A. Gutiérrez. 2013. Understanding Pulp Delignification by Laccase-Mediator Systems through Isolation and Characterization of Lignin-Carbohydrate Complexes Biomacromolecules 14: 3073-3080. Eriksson K.E.L. and R.A. Blanchette. 1990. Microbial and enzymatic degradation of wood and components. Springer-Verlag, Berlin, Heidelberg, New York, London, Paris, Tokyo, Hong Kong.

Galliano H., G. Gass, J.L. Seris and A.M. Boudet. 1991. Lignin degradation by Rigidoporus lignosus involves synergistic action of two oxidizing enzymes: Mn peroxidase and laccase. Enzyme Microb. Technol. 13: 478-482.

Hofrichter M. 2002. "Review: lignin conversion by manganese peroxidase (MnP)”. Enzyme and Microbial Technology 30: 454-66.
Huttermann A., C. Mai and A. Kharazipour. 2001. Modification of lignin for the production of new compounded materials. Apply Microbiol. Biotechnol. 55: 387-394.

Jung H., F. Xu and K. Li. 2002. Purification and characterization of laccase from wood-degrading fungus Trichophyton rubrum LKY-7. Enzyme Microbial. Tech. 30: 161-168.

Karp S.G., V. Faraco, A. Amore, L. Birolo, C. Giangrande, V.T. Soccol, A. Pandey and C.R. Soccol. 2012. Characterization of laccase isoforms produced by Pleurotus ostreatus in solid state fermentation of sugarcane bagasse. Bioresour Technol. 114: 735-739. Koroleva O.V., E.V. Stepanova, V.P. Gavrilova, N.S. Yakovleva, E.O. Landesman, I.S. Yavmetdinov and A. Yaropolov. 2002. Laccase and Mn-peroxidase production by Coriolus hirsutus strain 075 in a jar fermentor. J. Bioscience Bioengineering 5: 449-452.

Krajewski A. and P. Witomski. 2003. Protection of Wood, Ed. $S G G W$-Warsaw (in Polish) p. 271.

Kunamneni A., F.J. Plou, A. Ballesteros and M. Alcalde. 2008. Laccases and their applications: A patent review, Departamento de Biocatálisis, Instituto de Catálisis y Petroleoquímica, CSIC, Cantoblanco, 28049 Madrid, Spain. http://digital.csic.es/bitstream/10261/9595/1/postprint_laccase_patent_review.pdf

Leonowicz A. and K. Grzywnowicz. 1981. Quantitative estimation of laccase forms in some white-rot fungi using syringaldazine as a substrate. Enzyme. Microb. Technol. 3: 55-57.

Lettera V., A. Piscitelli, G. Leo, L. Birolo, C. Pezzella and G. Sannia. 2010. Identification of a new member of Pleurotus ostreatus laccase family from mature fruiting body. Fungal Biol. 114: 724-730. Libardi N.Jr., R.M. Gern, S.A. Furlan and D. Schlosser. 2012. Laccase production by the aquatic ascomycete Phoma sp. UHH 5-1-03 and the white rot basidiomycete Pleurotus ostreatus DSM 1833 during submerged cultivation on banana peels and enzyme applicability for the removal of endocrine-disrupting chemicals. Appl. Biochem. Biotechnol. 167: 1144-1156.

Mayer A.M. and R.C. Staples. 2002. Laccase: New function for an old enzyme. Phytochemistry 60: 551-565.

Michael J.F.C., S.D. Dass, E.A. Grulke and C.A. Reddy. 1991. Role of manganese proxidases and lignin peroxidases of Phanerochaete chrysosporium in the decolorization of kraft bleach plant effluent. Appl. Environ. Microbiol. 57: 2368-2375.

Morais H., C. Ramos, E. Forgack, T. Csershati and J. Oliviera. 2001. Lignin-modifying enzymes of Pleurotus ostreatus grown on agro-residues. Acta Alimentaria 30: 363-372.

Nazareth S.W. and J.D. Sampy. 2003. Production and characterisation of lignocellulases of Panus tigrinus and their application. International Biodeterioration and Biodegradation 52: 207-214.

Niku-Paavola M.L, M. Raaska and M. Itavara. 1990. Detection of white-rot fungi by a nontoxic stain. Mycol. Res. 94: 27-31.

Riva S. 2006. Laccases: blue enzymes for green chemistry. Trends Biotechnol. 24: 219-226.

Ruttimann-Johnson C., L.Salas, R.Vicuna and T.K. Kirk. 1993. Extracellular enzyme production and synthetic lignin mineralization by Ceriporiopsis subvermispora. Appl. Environmental Microbiology 59: 1792-1797.

Sanchez C. 2009. Lignocellulosic residues: Biodegradation and bioconversion by fungi. Biotechnology Advances 27: 185-194.

Shah M.P., G.V. Reddy, R. Banerjee, P.R. Babu and I.L. Kothari. 2005. Microbial degradation of banana wastes under solid state bioprocessing using two lignocellulolytic fungi Phylostica spp. MPS-001 and Aspergillus spp. MPS-002. Process Biochemistry 40: 445-451.

Shi Y.F., Y. Hui-Sheng and J.A. Buswell. 1997. Effect of nutrient nitrogen and manganese on manganese peroxidase and laccase production by Pleurotus sajor-caju, FEMS Microbiology Letters 147: 133-137. Toczko M. and A. Grzelińska. 1997. Materials from Biochemistry. ed. SGGW, Warsaw (in Polish) book for students.

Zadrazil F. 1975. Influence of $\mathrm{CO}_{2}$ concentration on the mycelium growth of three Pleurotus species. European J. Appl. Microbiol. 1: 327-335. 
